\title{
Trois disques de musique amérindienne
}

\section{Michel Plisson}

\section{(2) OpenEdition \\ Journals}

Édition électronique

URL : http://journals.openedition.org/ethnomusicologie/1303

ISSN : 2235-7688

Éditeur

ADEM - Ateliers d'ethnomusicologie

Édition imprimée

Date de publication : 1 décembre 1996

Pagination : 346-349

ISBN : 978-2-8257-0559-9

ISSN : $1662-372 X$

Référence électronique

Michel Plisson, «Trois disques de musique amérindienne », Cahiers d'ethnomusicologie [En ligne],

9 | 1996, mis en ligne le 05 janvier 2012, consulté le 20 avril 2019. URL : http://

journals.openedition.org/ethnomusicologie/1303

Ce document a été généré automatiquement le 20 avril 2019.

Tous droits réservés 


\title{
Trois disques de musique amérindienne
}

\author{
Michel Plisson
}

\section{RÉFÉRENCE}

Brésil : Asurini et Arara. Enregistrements, texte et photographies : Jean-Pierre Estival. 1 CD OCORA C 560084, 1995. Durée totale 66'30".

Equateur : Le monde sonore des Shuars. Enregistrements et textes : Pierre Salivas. 1 CD BUDA 92638-2, 1995. Durée totale 72'43".

Brésil : Enauené-Naué et Nhambiquara du Mato-grosso. Enregistrements, texte et photographies : Luis Fernandez (1982-1994). 1 CD VDE-GALLO CD-875, Archives internationales de musique populaire, Musée d'ethnographie Genève, AIMP XLIII, 1995. Durée totale 67'21".

1 La discographie amérindienne s'enrichit de trois albums qui nous permettent de pénétrer quelque peu dans l'univers sonore de ces cultures dont il nous faut encore répéter qu'elles sont, à court terme, menacées de disparition. Il s'agit bien d'« univers sonore » tant la production musicale est ritualisée dans ces sociétés. On sait que le terme même de musique ne trouve pas d'équivalent dans les cultures amérindiennes. Patrick Menget révèle qu'en langue Txicao (Musique du Haut-Xingu, Ocora C 580022, 1992) le terme orignang signifie à la fois «il joue d'un instrument ", «il chante ", et "il danse dans une fête ». Jean-Pierre Estival souligne également que les productions musicales des Indiens Asurinisont toujours centrées autour des rituels. Les Amérindiens ont de l'univers une perception musicale. Ainsi ces musiques sont (presque) toujours l'expression symbolique des forces cosmiques que l'homme cherche à se concilier et non à s'approprier, tant est peu développé le sentiment de propriété dans les cultures d'Amazonie. Grâce à ces trois $\mathrm{CD}$, l'auditeur se projettera dans le monde sonore des Amérindiens tout comme le héros $\mathrm{du}$ « Partage des eaux » d'Alejo Carpentier, qui, à la poursuite d'un idiophone amérindien, alliance singulière de bâton de rythme et de tambour, plongera finalement dans le xvi ${ }^{\mathrm{e}}$ siècle de la Conquête. 
2 Pratiquer le rituel, et donc pratiquer la musique, c'est procéder à une manifestation explicite où sont mises en jeu les forces telluriques dont l'homme doit toujours s'efforcer de conserver l'équilibre. C'est précisément la fonction des chants roia des Bororos (Le monde sonore des Bororos, Auvidis/Unesco D 8201, 1989). Dans la culture Asurini, le rituel tule qui dure plusieurs mois procède de la même relation. La production musicale ritualisée comme manifestation symbolique explicitée du monde se retrouve dans la culture Shuar telle que nous la décrit Pierre Salivas. Chez les Enauené-Naué comme chez les Nhambiquara du Mato-Grosso, la maison des flûtes se trouve au centre du village et renferme les instruments utilisés pour des rituels qui peuvent durer plusieurs mois.

3 Si pratiques musicales et rituels sont indissociés et indissociables chez les Amérindiens, ces univers sonores sont musicalement très diversifiés, c'est ce qui ressort de l'écoute de ces trois remarquables albums.

4 Les clarinettes tule sont les intruments privilégiés des Asurini appartenant au groupe linguistique tupi-guarani. Ces tule dont le timbre nous fait parfois penser à la clarinette basse qu'utilisent certains musiciens de jazz possède une densité sonore étonnamment forte. Chaque instrument n'émettant qu'un son, ces tule se jouent en général à plusieurs. Ici, la pratique musicale est donc essentiellement collective. La beauté vient du timbre grave de ces instruments et de leur masse sonore qui impressionnent fortement l'auditeur. Le lien avec l'univers s'établit d'emblée, car chaque pièce est consacrée à un animal particulier. A côté des Asurini du Xingu, aujourd'hui réduits à une soixantaine d'individus, vivent leurs cousins du rio Trocara, guère plus nombreux, et dont le CD a retenu des " pièces rares ». Le terme de " pièces rares ", qui peut évoquer pour certains la poésie musicale d'Erik Satie, s'applique particulièrement bien à ces étranges morceaux de tule de couleur sombre, doublés, de curieuse façon, par des flûtes. « Rares », parce que peu nombreuses, ces pièces le sont aussi par leur étrangeté.

5 Le CD contient également des pièces musicales des Arara, appartenant au groupe linguistique karib qui vivent sur un affluent du Xingu. Les clarinettes tagat tagat y côtoient d'autres aérophones. Retenons de ces pièces enregistrées un certain rituel de retour de chasse où les tagat tagat se mélangent aux sifflets tsingule et qui, un certain jour, laissa un souvenir inoubliable à l'ethnologue.

6 Toutes ces clarinettes tule émettent des harmoniques nombreuses, particulièrement riches, remplissant pleinement le spectre musical, comme l'explique l'auteur dans un article publié dans les Cahiers (Estival 1993). La contradiction apparente entre l'aspect rudimentaire de ces instruments et la richesse des harmoniques qu'ils produisent est peut-être à l'origine de l'émotion esthétique que ressent l'auditeur à l'écoute de ces musiques.

7 Dans le monde sonore des Amérindiens Shuar, les musiques des basses-terres du HautAmazone sont étroitement liées à l'organisation sociale des groupes humains. La façon de concevoir l'«autre " monde trouvant dans tous les cas de manière univoque une expression sonore formelle particulière. Si les Asuriniétaient environ 40 en 1989, on comptait à la même date à peu près 45000 Shuar répartis de chaque côté de la frontière entre le Pérou et l'Equateur. Cette culture n'est donc pas directement menacée, du moins dans un avenir proche. Leur univers sonore correspond assez bien à ce que l'ethnomusicologue argentin Carlos Vega formalisa jadis comme univers musical tritónico par référence formelle au pentatonisme que Brailoiu étudiait en Europe et que Raoul et Marguerite d'Harcourt relevèrent dans les Andes au début du siècle. De fait, les 
intervalles de quinte, d'octave et de tierce sont fréquents, sinon dominants, comme le montrent fort bien les transcriptions figurant dans le livret. Dans cette musique shuar, il n'existe apparemment pas d'influence directe du pentatonisme malgré la proximité des Andes. Seule exception, la conque marine pututu commune aux deux cultures.

Le «monde sonore» shuar semble basé sur une opposition binaire magique/ profane, masculin/féminin, que l'on retrouve dans la vie matérielle des Shuar comme dans leur musique. Ce sont les nampet et les anent, ces chants magiques que l'on ne chante jamais en public et dont Philippe Descola nous dit qu'ils sont les « vecteurs privilégiés de l'activité de contrôle symbolique déployés par les hommes et les femmes ». Pour les Shuar, cette pratique musicale est nécessaire pour maintenir l'ordre du cosmos, ainsi que le relate ce beau mythe selon lequel les Shuar doivent chanter des anent à la déité Nunkui pour qu'elle ne les laisse jamais manquer de nourriture.

9 Les pièces enregistrées montrent à l'évidence la richesse de l'univers sonore des Shuars : flûtes, arc musical, et surtout chants de femmes. Que tout événement de la vie des Shuar soit prétexte à pratique musicale, on n'en doutera guère devant l'excellence des interprètes. Ces voix féminines nous font pénétrer dans le monde sonore des Shuar, et du même coup, dans leur culture. Nous n'avions jusqu'à présent que peu de documents sonores sur ces hommes de la forêt. C'est donc à plus d'un titre que le disque de Pierre Salivas, très bien enregistré, fera date dans l'ethnomusicologie amérindienne.

Comme la plupart des ethnies amérindiennes, les Enauéné-naué et Nhambiquara du Mato-Grosso brésilien ont eu à souffrir de l'avancée du front de colonisation des Blancs et de la chute démographique qui s'en est suivie. Luis Fernandez, ethnomusicologue espagnol établi en Suisse et auteur de cet album, évalue aujourd'hui à 250 les EnauenéNaué et à moins de 1000 les Nhambiquara. Pourtant, leur musique témoigne de la vitalité de leur culture. Selon l'auteur, ces peuples, quoique de langue et de culture différentes ont en commun d'avoir subi l'influence de la nation Pareci, importante ethnie du MatoGrosso central, ce qui justifie le regroupement de ces musiques dans un seul album.

11 Le rituel yaunkwá dont le CD contient des extraits musicaux, dure six mois. Il commence en décembre avec le maïs nouveau, époque à laquelle les femmes fabriquent la bière hetera. Les instruments, entreposés dans la "maison des flûtes », au centre du village, se mettent à jouer pour la circonstance. L'univers sonore du rituel se compose de flûtes et de chants. La remarquable prise de son du CD rend saisissant "l'ambiance du yaunkwá » enregistré à $4 \mathrm{~h}$ du matin, loin du regard des femmes à qui il est interdit de voir les flûtes, sous peine d'être assommées. Des sons étranges éveillent en nous des émotions curieuses, comme cet altérateur de voix utilisé par les Enauené-Naué et qui représente la voix des esprits, ou ces clarinettes d'eau au rythme curieusement syncopé.

12 La richesse musicale des Nhambiquara contraste avec une vie matérielle assez rudimentaire. Les Pareci les nommaient waikoakoré (ceux qui dorment à même le sol) et Lévi-Strauss soulignait, dans les années cinquante, l'équilibre précaire que les Nhambiquara entretenaient avec le milieu ambiant. Les groupes qui nomadisent dans la forêt sont en général d'effectifs réduits, vingt-cinq en moyenne contre cinquante à soixante pour d'autres ethnies d'Amazonie. Une fécondité de deux à trois enfants et des prohibitions sexuelles drastiques comme celle de l'interdiction de relations avant le sevrage du dernier nouveau-né font des Nhambiquara un groupe culturellement fragile. Relevons aussi cette étrange coutume selon laquelle les individus ne peuvent s'appeler entre eux par leur nom, lequel doit rester confidentiel. Cette ethnie fruste qui ignore la pirogue et le hamac, pourtant partout répandus dans les basses-terres subtropicales, 
possède en revanche une langue complexe et des pratiques musicales variées. De fait, les Nhambiquara« ont peu de chances d'être de vrais primitifs » ainsi que l'écrivait déjà LéviStrauss - non sans humour - il y a plus de quarante ans. Les chants chamaniques et les flûtes nasales nhambiquara nous introduisent dans un univers sonore unique, bien décrit par un livret au texte clair et copieux, illustré d'excellentes photos.

\section{BIBLIOGRAPHIE}

CARPENTIER Alejo, 1955, Le partage des eaux. Traduction française 1956. Paris : Gallimard.

DESCOLA Philippe, 1986, La nature domestique : symbolisme et praxis dans l'écologie des Achuars. Paris : Editions de la maison des sciences de l'homme.

DESCOLA Philippe, 1993, Les lances des crépuscules. Paris : Plon, collection Terres humaines.

ESTIVAL Jean-Pierre, 1991, « La musique instrumentale dans un rituel Arara de la saison sèche (Pará, Brésil) ». Journal de la société des américanistes LXXVII : 125-156.

ESTIVAL Jean-Pierre, 1993 «Quelques aspects des polyphonies instrumentales tule des Asurini du Moyen-Xingu (Brésil) ». Cahiers de musiques traditionnelles 6 : 163-179.

ESTIVAL Jean-Pierre, 1994, Musiques instrumentales Asurini du Moyen-Xingu et de l'Iriri (Pará/ Brésil). Thèse de doctorat. Université Paris X Nanterre. 